\title{
Qualitative Phytochemical Screening and Antioxidant Activities from Three Different Citrus Leaves (Rutaceae)
}

\author{
Nur Irdeena. Z. ${ }^{1}$, Norhayati. Y. ${ }^{1}$, Syara K. ${ }^{1,2}$, Nurul Huda A.W. ${ }^{1,2^{*}}$ \\ ${ }^{\text {I}}$ Faculty of Science \& Marine Enviroment, Universiti Malaysia Terengganu, 21030, Terengganu, Malaysia. \\ ${ }^{2}$ Advanced Nano Materials (ANoMa) Research Group, Universiti Malaysia Terengganu, 21030, Terengganu, Malaysia. \\ Corresponding:nhuda@umt.edu.my
}

\begin{abstract}
Leaves of Citrus aurantifolia, Citrus hystrix and Citrus microcarpa collected from Mersing, Johor were selected for this research. The extraction of these samples were carried out using three different polarities of solvents (hexane, ethyl acetate, and methanol). Phytochemical screening were done with various test for each of crude extracts. The results showed that $C$. aurantifolia gave positive result for alkaloids, saponins, reducing sugar and carbohydrates in hexane and ethyl acetate extracts. In contrast to $C$. hystrix where the presence of alkaloids, steroids, reducing sugar and carbohydrates were proven in all crude extracts. Lastly, C. microcarpa showed positive result for alkaloids, triterpenoids, saponins, flavonoids, reducing sugar, carbohydrates, phenolic content, glycosides and tannins for hexane and ethyl acetate crude extracts. Through antioxidant assays measured at wavelength $234 \mathrm{~nm}, C$. aurantifoliaa has the highest AOA which was 10. The scavenging effect on DPPH radical was done at the wavelength of $517 \mathrm{~nm}$ and $C$. microcarpa has the highest percentage of scavenging effect with $96.41 \%$. Next, the non-enzymatic antioxidant assays on the determination of $\alpha$-tocopherol and carotenoids showed that $C$. hystrix has the highest concentration of $\alpha$-tocopherol $(2.30 \pm 0.026)$, while $C$. microcarpa has the highest concentration of carotenoids $(18.40 \pm 2.83)$.
\end{abstract}

Keywords: Citrus aurantifolia; Citrus hystrix; Citrus microcarpa; phytochemical; antioxidant properties

\section{Introduction}

Rutaceae family is a flowering plants containing with 158 genera and 1730 species and distributed in Africa and Australia, or in warm temperature and tropical regions (Shivakumar et al., 2016). Rutaceae family members has aromatic leaves due to the presence of oil glands on its surfaces. The species that commonly used are lemon (Citrus limon), lime (Citrus aurantifolia), sweet orange (Citrus sinensis), sour orange (Citrus aurantium), tangerine (Citrus reticulata) and grapefruit (Citrus paradisi). The other species are citron (Citrus medica), chinotto (Citrus myrtifolia), bergamot (Citrus bergamia), and shaddock (Citrus maxima) (Scordino \& Sabatino, 2014). As in this study, there are three selected plants from rutaceae family were used for further analysis of secondary metabolites and biological activities. The selected plant which are key lime (Citrus aurantifolia), kaffir lime (Citrus hystrix) and calamansi (Citrus microcarpa).

\section{Materials and Methods}

\subsection{Plant materials}

The selected plant which are key lime (Citrus aurantifolia), kaffir lime (Citrus hystrix) and calamansi (Citrus microcarpa) were collected from Mersing, Johor, Malaysia.

\subsection{Chemical and reagents}

Wagner's reagent, ethanol, ethanol absolute, sodium phosphate buffer, tris-HCl buffer, L-ascorbic acid, 2.2-diphenyl-1-picrylhydrazyl (DPPH), linoleic acid, Tween-20, butyl-hydroxytoluene (BHT), ferric chloride, orthophosphoric acid, $\alpha$-tocopherol, cytochrome C, 3-(2-pyridyl)-5,6-diphenyl-1.2.4triazine-p (PDT) and trycholoroacetic acid (TCA).

\subsection{Sample Extraction}

The leaves powder were extracted in three different solvent with increasing polarity (hexane, ethyl acetate and methanol) at room temperature for two days. The samples were extracted in hexane for 2 days and were filtered. Next, the residue were soaked in ethyl acetate and left for 2 days. The same step were repeated using methanol. Then, each extract was concentrated using rotary evaporator under the condition of reduced pressure at $35-40^{\circ} \mathrm{C}$.

\subsection{Phytochemical Screening}

\subsubsection{Alkaloids Test (Wagner Test)}

Crude extracts were added with Wagner's reagent. The formation of reddish brown precipitate indicates the presence of alkaloids. 


\subsubsection{Triterpenoids / Steroids Test}

Crude extracts were added with $20 \mathrm{~mL}$ of ethanol and were boiled in water bath. After filtration and vaporization, $10 \mathrm{~mL}$ of diethyl ether were added into the residue and filtered again. The filtrate were dried at room temperature. 3-5 drops of acetic acid were added and followed by addition of 1-2 drops of concentrated sulphuric acid. The formation of blue or greenish blue colour justified the presence of steroids while the formation of red colour indicates the presence of triterpenoids.

\subsubsection{Saponins Test (Foam Test)}

Crude extracts were shaken with distilled water and heated until boil. The formation of bubbles indicates the presence of saponins.

\subsubsection{Flavonoids Test $\left(\mathrm{H}_{2} \mathrm{SO}_{4}\right.$ Test $)$}

Crude extracts were treated with few drops of $\mathrm{H}_{2} \mathrm{SO}_{4}$. The formation of orange colour indicates the presence of flavonoids.

\subsubsection{Phlobatannins Test}

Crude extracts were dissolved in distilled water and filtered. The filtrate were boiled with $2 \mathrm{M} \mathrm{HCl}$ solution. Formation of red precipitate shows the presence of phlobatannins.

\subsubsection{Reducing Sugar Test}

Crude extracts were shaken with distilled water and filtered. The filtrate were boiled with drops of Fehling's solution for a few minutes. The presence of reducing sugar were proven with the formation of orange red precipitate.

\subsubsection{Carbohydrates Test (Iodine Test)}

Crude extracts were dissolved in $5 \mathrm{~mL}$ of distilled water and filtered. Then, 2-3 drops of $\mathrm{FeCl}_{3}$ were added into the filtrate and boiled in water bath. Formation of blue black colour indicates the presence of carbohydrates.

\subsubsection{Phenolic Content Test}

Crude extracts were dissolved with $5 \mathrm{~mL}$ distilled water and 2-3 drops of $10 \%$ iron (III) chloride solution were added into the mixture. Then, the positive result of phenolic content were determined when the colour of the solution changed to blue or green colour.

\subsubsection{Glycosides Test}

Crude extracts were dissolved in $20 \mathrm{~mL}$ distilled water and were added with 3-5 drops of bromine water. The formation of yellow precipitate indicates the presence of glycosides.

\subsubsection{Tannins Test}

Crude extracts were dissolved in $2 \mathrm{~mL}$ of distilled water and 2-3 drops of diluted $\mathrm{FeCl}_{3}$ were added into the mixture. Then, the presence of tannins were proven with the formation of blue or green colour solution.

\subsection{Antioxidant Activity}

Crude extracts $(0.1 \mathrm{~mL})$ were mixed with $2 \mathrm{~mL} 10 \mathrm{M}$ $(\mathrm{pH}$ 6.5) linoleic acid emulsion in a test tube and placed in dark place at temperature $37^{\circ} \mathrm{C}$ to increase oxidation process. The absorbance before oxidation was measured at $234 \mathrm{~nm}$. Before mixing the extract, linoleic acid was prepared by dissolving $0.2804 \mathrm{~g}$ linoleic acid and $0.2804 \mathrm{~g}$ Tween-20 in $50 \mathrm{~mL}, 0.2 \mathrm{M}$ sodium phosphate buffer ( $\mathrm{pH}$ 6.5). After incubation for 15 hours, $6 \mathrm{~mL}$ of $60 \%$ methanol was added and mixed thoroughly. The absorbance of the mixture after oxidation was measured at $234 \mathrm{~nm}$.

The antioxidant activity were calculated by using this formula:

$$
\mathrm{AOA}=\frac{(\Delta \mathrm{A} 234 \text { of control }-\Delta \mathrm{A} 234 \text { of sample })}{(\Delta \mathrm{A} 234 \text { of control })}
$$

An antioxidant activity value of 1 indicates the strongest antioxidant activity.

\subsection{Free Radical Scavenging Assays}

\subsubsection{Scavenging Effect on DPPH Radical}

$1 \mathrm{~mL}$ of crude extracts were mixed with $0.25 \mathrm{~mL}$ $0.2 \mathrm{M}$ DPPH radicals in methanol solution. The mixture was shaken vigorously and left to stand for 30 minutes at room temperature. The reduction of DPPH was measured by reading the absorbance at $517 \mathrm{~nm}$. $1 \mathrm{~mL}$ of $\alpha$-tocopherol and BHT were used at $20 \mathrm{M}$ in methanol as controls.

The scavenging effect on DPPH radical (\%) was calculated using the formula:

$$
\text { Scavenging effect }(\%)=\frac{A-A 1}{A} \times 100 \%
$$

Where A was the absorbance of the control, and A1 was the absorbance of the test sample.

\subsection{Non-enzymatic Antioxidant Assays}

\subsubsection{Determination of $\alpha$-Tocopherol}

$0.5 \mathrm{~mL}$ of the hexane extract was added into $0.4 \mathrm{~mL}$ of $0.1 \%(\mathrm{w} / \mathrm{v})$ PDT (3-(2-pyridyl)-5,6-diphenyl1,2,4-triazine-p in ethanol) and $0.4 \mathrm{~mL}$ of $0.1 \%$ (w/v) ferric chloride (in ethanol). The volume were made up to $3.0 \mathrm{~mL}$ with absolute ethanol and the mixture was gently swirled and left for 4 minutes for colour changes. Next step, $0.2 \mathrm{~mL}$ of $0.2 \mathrm{M}$ orthophosphoric acid was added into the mixture and allowed to stand for 30 minutes at room temperature. The absorbance of the mixture were measured at $554 \mathrm{~nm}$ after the process. The blank was prepared in the same method except absolute ethanol was used instead of hexane 
extracts. A standard curve was prepared using $\alpha$ tocopherol at various concentrations. Then, $0.5 \mathrm{~mL}$ of $\alpha$-tocopherol in the leaf samples were calculated based on the standard curve.

\subsubsection{Determination of Carotenoids}

$0.02 \mathrm{~g}$ of leaf tissue were ground up with $3.0 \mathrm{~mL}$ of $80 \%(\mathrm{v} / \mathrm{v})$ acetone in a mortar and pestle under condition dim light and over ice. Then, the homogenate was centrifuged at $10,000 \mathrm{rpm}$ for 10 minutes. The absorbance of the supernatant was measured at 663.2, 646.8, and $470 \mathrm{~nm}$. As a blank, $80 \%$ acetone was used.

Carotenoids content was calculated using formula:

$\mathrm{Ca}=12.25 \mathrm{~A}_{663.2}-2.79 \mathrm{~A}_{646.8}$

$\mathrm{Cb}=21.50 \mathrm{~A}_{646.8}-5.10 \mathrm{~A}_{663.2}$

$$
\mathrm{Cx}+\mathrm{c}=\frac{1000 \mathrm{~A}_{470}-1.82 \mathrm{Ca}-85.02 \mathrm{Cb}}{198}
$$

Where Ca: chlorophyll a (mg/L)

$\mathrm{Cb}$ : chlorophyll b (mg/L)

$\mathrm{Cx}_{+} \mathrm{c}$ : carotenoids $(\mathrm{mg} / \mathrm{mL})$

\section{Results and Discussions}

\subsection{Phytochemical Screening}

Phytochemical screening test were done to determine the presence of secondary metabolites in Citrus aurantifolia, Citrus hystrix and Citrus microcarpa leaves. Each of the leaves sample has three different polarities of crude extract that made the total of nine crude extracts. The test were conducted consist of Alkaloid Test, Triterpenoids Test, Steroids Test, Saponins Test, Flavanoids Test, Phlobatannins Test, Reducing Sugar Test, Carbohydrates Test, Phenolic Content Test, Glycosides Test and Tannins Test. Table 1, 2 and 3 shows the summarize of phytochemical test for all the crude extracts of $C$. aurantifolia, $C$. hystrix and C. microcarpa respectively.
Table 1 Results of Citrus aurantifolia sp.

\begin{tabular}{|c|c|c|c|}
\hline $\begin{array}{c}\text { Phytochemical } \\
\text { Test }\end{array}$ & \multicolumn{3}{|c|}{ Citrus aurantifolia } \\
\cline { 2 - 4 } & Hexane & $\begin{array}{c}\text { Ethyl } \\
\text { Acetate }\end{array}$ & $\mathrm{MeOH}$ \\
\hline Alkaloids & + & + & - \\
\hline Triterpenoids & - & + & - \\
\hline Steroids & + & - & - \\
\hline Saponins & + & + & - \\
\hline Flavonoids & + & - & - \\
\hline Phlobatannins & - & - & - \\
\hline Reducing Sugar & + & + & - \\
\hline Carbohydrates & + & + & - \\
\hline $\begin{array}{c}\text { Phenolic } \\
\text { Content }\end{array}$ & - & + & - \\
\hline Glycosides & + & - & - \\
\hline Tannins & - & + & - \\
\hline$+:$ Positive result & \multicolumn{2}{|c}{ Negative result }
\end{tabular}

Table 2 Results of Citrus hystrix sp.

\begin{tabular}{cccc}
\hline \multirow{2}{*}{$\begin{array}{c}\text { Phytochemical } \\
\text { Test }\end{array}$} & Hexane & $\begin{array}{c}\text { Ethyl } \\
\text { Acetate }\end{array}$ & $\mathrm{MeOH}$ \\
\cline { 2 - 4 } & & + & + \\
Alkaloids & + & - & - \\
Triterpenoids & - & + & + \\
Steroids & + & - & - \\
Saponins & + & - & + \\
Flavonoids & + & - & - \\
Phlobatannins & - & + & + \\
Reducing Sugar & + & + & + \\
Carbohydrates & + & - & - \\
Phenolic & - & - & + \\
Content & & - & - \\
Glycosides & + & - & Negative result
\end{tabular}

Table 3 Results of Citrus microcara sp.

\begin{tabular}{cccc}
\hline \multirow{2}{*}{ Phytochemical } & \multicolumn{3}{c}{ Citrus microcarpa } \\
\cline { 2 - 4 } Test & Hexane & Ethyl & MeOH \\
\hline Alkaloids & + & + & - \\
Triterpenoids & + & + & - \\
Steroids & - & - & - \\
Saponins & + & + & - \\
Flavonoids & + & + & + \\
Phlobatannins & - & - & - \\
Reducing Sugar & + & + & - \\
Carbohydrates & + & + & - \\
Phenolic & & + & - \\
Content & + & + & + \\
Glycosides & + & + & - \\
Tannins & + & + Negative result
\end{tabular}




\subsection{Antioxidant Activity}

Antioxidant helps to cure diseases that was caused by free radicals by preventing oxidation from happened (Pinchuk et al., 2012). The radicals were highly reactive to chemical produced by the cell in the body, and they destroyed cells, organelles, DNA and other biomolecules inside human body. The diseases which a person can get such as cancer and neurodegenerative (Ahmed et al., 2015). As stated by Loganayaki et al., (2013), secondary metabolites such as alakloids, flavonoids, saponins, phlobatannins and glycosides were essential to prevent free radical from undergoes oxidation process. Thus, antioxidant activity, scavenging effect on DPPH radical, and non-enzymatic antioxidant assays on determination of $\alpha$-tocopherol and carotenoids were carried out to determine the level of antioxidant activity in the leaves sample.

For antioxidant activity (AOA), the absorbance of the extracts after oxidation process were measured at $234 \mathrm{~nm}$. The result shows that Citrus aurantifolia has the highest antioxidant activity which was 10 ($2.35 \pm 0.041$ ) where since the leaves showed positive result on phenolic content test, it was proven by the test. Meanwhile, Citrus microcarpa has the lowest antioxidant activity, $0.6(0.11 \pm 0.005)$ and Citrus hystrix is at moderate antioxidant activity which is $1.55 \pm 0.027$. Table 4 shows the result of antioxidant activity and Figure 4 is the bar graph for antioxidant activity.

Table 4 Result of antioxidant activity (AOA)

\begin{tabular}{ccc}
\hline Samples & Mean \pm SD & AOA \\
\hline Citrus aurantifolia & $-2.35 \pm 0.041$ & 10 \\
Citrus hystrix & $-1.55 \pm 0.027$ & 7 \\
Citrus microcarpa & $0.11 \pm 0.005$ & 0.6 \\
\hline
\end{tabular}

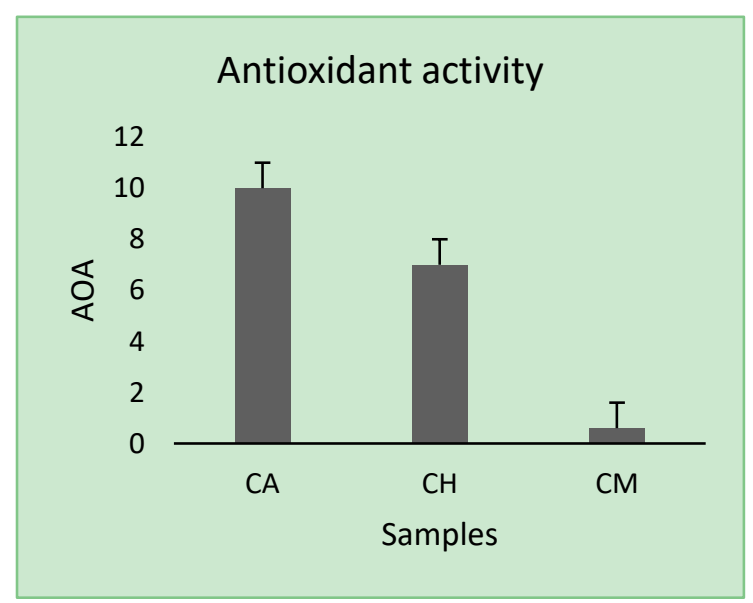

Fig. 4 Bar graph for antioxidant activity (AOA)

\subsection{Free Radical Scavenging Assays}

\subsubsection{Scavenging Effect on DPPH Radical}

In this assays, DPPH radical were used to determine the scavenging effect on the free radical at the absorbance of $517 \mathrm{~nm}$. DPPH radical is red in colour when it is stable and will change to yellow when it scavenged to an antioxidant. The reaction can be written as:

$$
\mathrm{DPPH}+\mathrm{H}-\mathrm{A} \longrightarrow \mathrm{DPPH}-\mathrm{H}+\mathrm{A}
$$

Citrus microcarpa has the highest percentage of scavenging effect with $96.41 \%$ and Citrus aurantifolia has the lowest percentage which was $75.68 \%$. Table 5 shows the difference of result on DPPH radical and Figure 5 shows the percentage of scavenging effect on DPPH radical.

Table 5 Result of scavenging effect on DPPH radical

\begin{tabular}{ccc}
\hline Samples & $\begin{array}{c}\text { Mean } \pm \\
\text { SD }\end{array}$ & $\begin{array}{c}\text { Percentage of } \\
\text { scavenging effect (\%) }\end{array}$ \\
\hline Citrus & $0.24 \pm$ & $75.68 \%$ \\
aurantifolia & 0.006 & \\
Citrus & $0.21 \pm$ & $79.01 \%$ \\
hystrix & 0.004 & \\
Citrus & $0.04 \pm$ & $96.41 \%$ \\
microcarpa & 0.001 & \\
\hline
\end{tabular}

\section{Percentage of scavenging effect on DPPH radical}

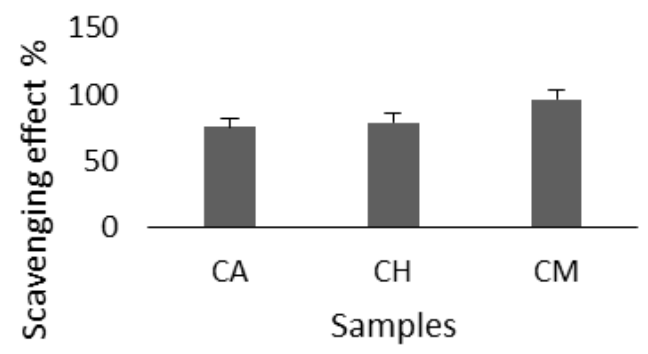

Fig. 5 Bar graph of percentage of scavenging effect

\subsection{Non-enzymatic Antioxidant Assays}

\subsubsection{Determination of $\alpha$-Tocopherol}

The determination of $\alpha$-tocopherol were measured at $554 \mathrm{~nm}$ and Citrus hystrix has the highest concentration of $\alpha$-tocopherol $(2.30 \pm 0.026)$ and Citrus aurantifolia has the lowest concentration $(0.51 \pm 0.021)$. Table 6 shows the result of determination of $\alpha$-tocopherol and Figure 6 shows the graph of concentration of $\alpha$-tocopherol. 
Table 6 Result of determination of $\alpha$-tocopherol

\begin{tabular}{cc}
\hline Samples & Mean \pm SD \\
\hline Citrus aurantifolia & $0.51 \pm 0.021$ \\
\hline Citrus hystrix & $2.30 \pm 0.026$ \\
\hline Citrus microcarpa & $1.11 \pm 0.032$ \\
\hline
\end{tabular}

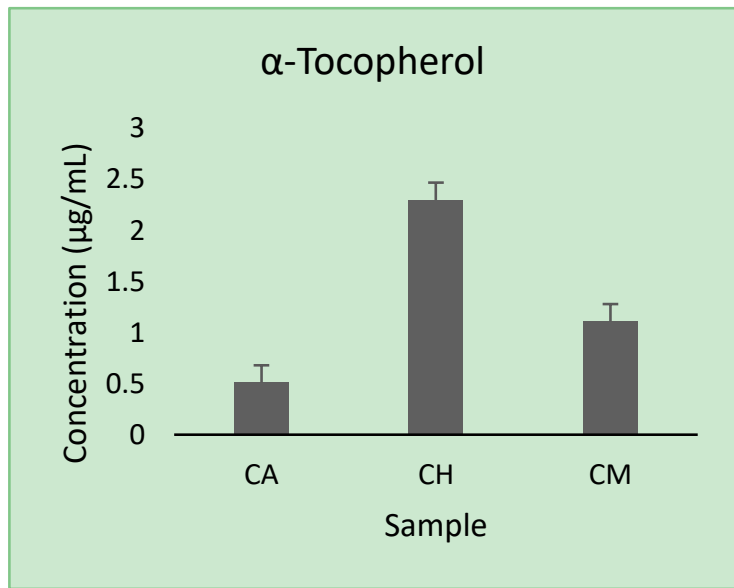

Fig. 6 Bar graph of concentration of $\alpha$-Tocopherol

\subsubsection{Determination of Carotenoids}

Carotenoids are the pigments that exist in animals, plants, microorganisms and marine creatures as its important roles as antioxidant (Young \& Lowe, 2018). Citrus microcarpa has the highest concentration of carotenoids which were $18.40 \pm$ 2.83 , followed by Citrus aurantifolia with $12.37 \pm$ 0.42 and lastly Citrus hystrix has the lowest concentration of carotenoids $(11.61 \pm 0.41)$. Table 7 shows the result of determination of carotenoid while Figure 7 shows the concentration of carotenoids.

Table 7 Result of determination of carotenoids

\begin{tabular}{cc}
\hline Samples & Mean \pm SD \\
\hline Citrus aurantifolia & $12.37 \pm 0.42$ \\
\hline Citrus hystrix & $11.61 \pm 0.41$ \\
\hline Citrus microcarpa & $18.40 \pm 2.83$ \\
\hline
\end{tabular}

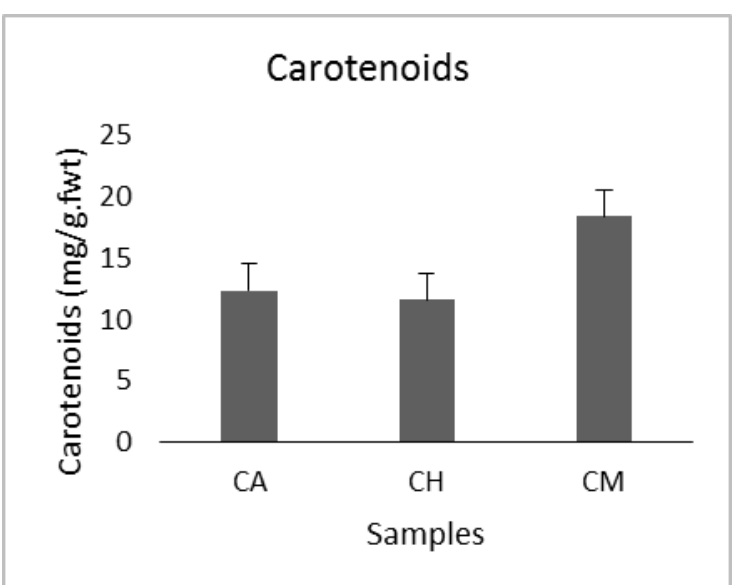

Fig. 7 Bar graph of concentration of carotenoids

\section{Conclusion}

Qualitative phytochemical screening test were carried out by 10 tests of secondary metabolites. Experimenting on phytochemical screening analysis revealed Citrus microcarpa leaves showed positive results on alkaloids, triterpernoids, saponins, flavonoids, reducing sugar, carboydrates, phenolic content, glycosides and tannins for hexane and ethyl acetate crude extracts. Meanwhile, Citrus hystrix contained with alkaloids, steroids, reducing sugar and carbohydrates in all crude extracts. Lastly, Citrus aurantifolia showed the presence of alkaloids, saponins, reducing sugar and carbohydrates in hexane and ethyl acetate crude extracts only.

Antioxidant activity showed that Citrus microcarpa has the highest antioxidant activity which was 0.6 $(0.11 \pm 0.005)$. Then, Citrus microcarpa has the highest percentage of scavenging effect on DPPH radical with $96.41 \%(0.04 \pm 0.001)$. Lastly, in the determination of $\alpha$-tocopherol and carotenoids, Citrus hystrix and Citrus microcarpa has the highest concentration of $\alpha$-tocopherol and carotenoids with $2.30 \pm 0.026$ and $18.40 \pm 2.83$ respectively.

\section{Acknowledgements}

The authors also would like to express their acknowledgment to Faculty of Science \& Marine Environment, University Malaysia Terengganu for providing laboratory facilities and to Ministry of Higher Education Malaysia for research grant FRGS 59391.

\section{References}

Ahmed, D., Khan, M., \& Saeed, R. (2015). Comparative Analysis of Phenolics, Flavonoids, and Antioxidant and Antibacterial Potential of Methanolic, Hexanic and Aqueous Extracts from Adiantum caudatum Leaves. Antioxidants, 4(2), 394-409.

Al-aamri, M. S., Al-abousi, N. M., Al-jabri, S. S., Alam, T., \& Khan, S. A. (2018). Chemical composition and in-vitro antioxidant and antimicrobial activity of the essential oil of Citrus aurantifolia L. leaves grown in Eastern Oman. Journal of Taibah University Medical Sciences, 0-4.

Butler, M. S. (2004). The role of natural product chemistry in drug discovery. Journal of Natural Products, 67(12), 2141-2153.

Chen, H. C., Peng, L. W., Sheu, M. J., Lin, L. Y., Chiang, H. M., Wu, C. T., Wu, C. S., \& Chen, Y. C. (2013). Effects of hot water treatment on the essential oils of calamondin. Journal of Food and Drug Analysis, 21(4), 363-368.

Cruz-Valenzuela, M. R., Tapia-Rodriguez, M. R., Vazquez-Armenta, F. J., Silva- 
Espinoza, B. A., Ayala-Zavala, J. F. (2016). Lime (Citrus aurantifolia) Oils. Essential Oils in Food Preservation, Flavor and Safety. Elsevier Inc.

Dias, D. A., Urban, S., \& Roessner, U. (2012). A Historical Overview of Natural Products in Drug Discovery. Metabolites, 2(4), 303-336.

Lee, S. W., \& Najiah, M. (2009). Antimicrobial Property of 2-Hydroxypropane-1,2,3Tricarboxylic Acid Isolated from Citrus microcarpa Extract. Agricultural Sciences in China, 8(7), 880-886.

Loganayaki, N., Siddhuraju, P., \& Manian, S. (2013). Antioxidant activity and free radical scavenging capacity of phenolic extracts from Helicteres isora L. and Ceiba pentandra L. Journal of Food Science and Technology, 50(4), 687-695.

Lu, Z. hua, Zhou, Z. qin, \& Xie, R. jin. (2011). Molecular Phylogeny of the "True Citrus Fruit Trees" Group (Aurantioideae, Rutaceae) as Inferred from Chloroplast DNA Sequence. Agricultural Sciences in China, 10(1), 49-57.

Panthong, K., Srisud, Y., Rukachaisirikul, V., Hutadilok-Towatana, N., Voravuthikunchai, S. P., \& Tewtrakul, S. (2013). Benzene, coumarin and quinolinone derivatives from roots of Citrus hystrix. Phytochemistry, 88, 79-84.

Pinchuk, I., Shoval, H., Dotan, Y., \& Lichtenberg, D. (2012). Evaluation of antioxidants:

Scope, limitations and relevance of assays. Chemistry and Physics of Lipids, 165(6), 638-647.

Scordino, M., \& Sabatino, L. (2014). Characterization of polyphenolic profile of citrus fruit by HPLC/PDA/ESI/MS-MS. Polyphenols in Plants: Isolation, Purification and Extract Preparation. Elsevier.

Shivakumar, V. S., Appelhans, M. S., Johnson, G., Carlsen, M., \& Zimmer, E. A. (2016). Analysis of whole chloroplast genomes from the genera of the Clauseneae, the curry tribe (Rutaceae, Citrus family). Molecular Phylogenetics and Evolution.

Young, A., \& Lowe, G. (2018). CarotenoidsAntioxidant Properties. Antioxidants, 7(2), 28. 